\title{
Analisis Business Model Canvas (BMC) Mie Tjap Tiga Anak Desa Wlahar Kulon Kecamatan Patikraja Kabupaten Banyumas
}

\author{
Analysis of Business Model Canvas (BMC) Mie Tjap Tiga Anak in Wlahar Kulon Village, \\ Patikraja District, Banyumas Regency
}

\author{
Rina Dwi Lestari ${ }^{1}$, Yusuf Enril Fathurrohman ${ }^{2}$ \\ ${ }^{1,2}$ Program Studi Agribisnis Fakultas Pertanian dan Perikanan \\ Universitas Muhammadiyah Purwokerto
}

\section{ARTICLE INFO \\ Article history: \\ DOI: \\ 10.30595/pspfs.v2i.205}

Submitted:

July 29, 2021

Accepted:

Sept 10, 2021

Published:

Nov 10, 2021

\section{Keywords:}

Canvas Model Business, Dry

Noodle, Tjap Tiga Anak

Noodle Factory

\begin{abstract}
This study aimed to analyze the design of the canvas business model of the Tjap Tiga Anak Noodle Factory. The method used was the descriptiveanalytical method because, in this study, a qualitative research type was chosen to analyze the Business Model Canvas to map the business state at the Mie Tjap Tiga Anak Factory. The results of research, at the Mie Tjap Tiga Anak Factory using a business model canvas, showed business activities in 9 elements, namely customer segments with B2C and B2B, value propositions that were certified halal (LPPOM MUI), channels used were direct and indirect, customer relationships with apply personal assistance, revenue streams were product sales, key resources were human resources, key activities were production activities, key partnerships were carried out with the government, distributors, and the community or customers, and the cost structure includes fixed and variable costs.
\end{abstract}

This work is licensed under a Creative Commons Attribution 4.0 International License.

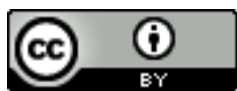

Corresponding Author:

Rina Dwi Lestari

Program Studi Agribisnis Fakultas Pertanian dan Perikanan

Universitas Muhammadiyah Purwokerto

Email: rinadwilestari2000@gmail.com

\section{PENDAHULUAN}

Mie merupakan salah satu produk pangan yang paling sering dikonsumsi oleh sebagian besar masyarakat baik sebagai makanan sarapan maupun sebagai makanan selingan (Purnawijayanti, 2009). Adapun jenis mie yang populer di pasaran adalah mie kering, yakni mie mentah yang dikeringkan hingga kadar air mencapai kisaran 8-10\% (Mariyani, 2011). Kebutuhan akan mie kering yang semakin bertambah didukung dengan data konsumsi mie kering dan mie instant menurut World Instant Noodles Asosiation (WINA) pada tahun 2018 mencapai 12,52 miliar bungkus.

Kabupaten Banyumas merupakan salah satu daerah yang memiliki produk mie sebagai kebanggaan lokal. Hal ini tentunya mendapatkan kebijakan dari pemangku wilayah, pemerintah Kabupaten Banyumas meminta agar toko-toko modern memberikan tempat untuk produk Usaha Mikro Kecil dan Menengah (UMKM) lokal. Disamping itu, dalam hal target pasarnya yang relatif terbatas dan biasanya diproduksi hanya untuk memenuhi kebutuhan disuatu wilayah tertentu saja yang berdekatan dengan lokasi pabriknya, salah satunya adalah pabrik Mie Tjap Tiga Anak.

Pabrik Mie Tjap Tiga Anak pertama kali diproduksi pada tahun 1925 yang berlokasi di desa Wlahar Kulon, Kecamatan Patikraja, Kabupaten Banyumas. Mie Tjap Tiga Anak ini cukup sederhana dalam proses 
pembuatannya dengan berbagai macam produk mie kering dengan pengolahan yang masih menggunakan cara tradisional. Produk Mie Tjap Tiga Anak ini sudah sampai ke kota-kota besar di Indonesia. Pabrik ini seharusnya mengembangkan teknologi dan inovasi dalam perkembangan produksi dan ekonomi serta daya saing dalam usaha bisnis. Hal tersebut tidak terlepas dari metode yang digunakan oleh perusahaan dalam menjalankan bisnisnya yang tersusun didalam model bisnis.

Model bisnis merupakan deskripsi suatu aktifitas bagaimana organisasi dalam menciptakan, menyampaikan, dan mengontrol nilai perusahaan dan bagaimana organisasi menghasilkan uang (Osterwalder \& Pigneur, 2010). Model bisnis perlu disusun sebagai evaluasi dan koreksi pada pabrik Mie Tjap Tiga Anak serta meningkatkan fungsi dan ekonomi pabrik Mie Tjap Tiga Anak memiliki orientasi pada pasar, dimana jumlah produksi yang dilakukan oleh pabrik disesuaikan dengan permintaan pasar dan daya beli konsumen sehingga dapat menemukan dan mengembangkan dalam keunggulan kompetitif perusahaan.

Salah satu cara untuk meninjau dan menggambarkan model bisnis seperti apa yang dimiliki oleh suatu perusahaan adalah dengan menggunakan Business Model Canvas (BMC). Business Model Canvas merupakan alat yang dapat menjanjikan untuk membuat dan mengevaluasi dalam model bisnis baru dengan mudah dan cepat (Wallin, Chirumalla, \& Thomson, 2013). Business Model Canvas menawarkan suatu kerangka kerja yang sangat berguna untuk menganalisis elemen-elemen dari model bisnis karena mengandung banyak elemen penting dalam bisnis (Anu H., 2010). Adapun sembilan elemen yang digunakan Mie Tjap Tiga Anak pada Business Model Canvas yang telah diterapkan yaitu mencakup customer segments, value propositions, channels, customer relationships, revenue streams, key resources, key activities, key partnerships, dan cost structure.

\section{METODE PENELITIAN}

Penelitian ini menggunakan metode deskriptif analitik. Metode deskriptif analitik digunakan dengan menerapkan beberapa analisis yang berkaitan dengan penelitian dengan cara menyusun data terlebih dahulu. Kemudian di analisis dan dilakukan interpretasi lebih dalam (Nazir, 1999). Metode deskriptif dipilih karena dalam penelitian ini dipilih jenis penelitian kualitatif karena ingin menganalisis Business Model Canvas untuk memetakan keadaan usaha pada Pabrik Mie Tjap Tiga Anak.

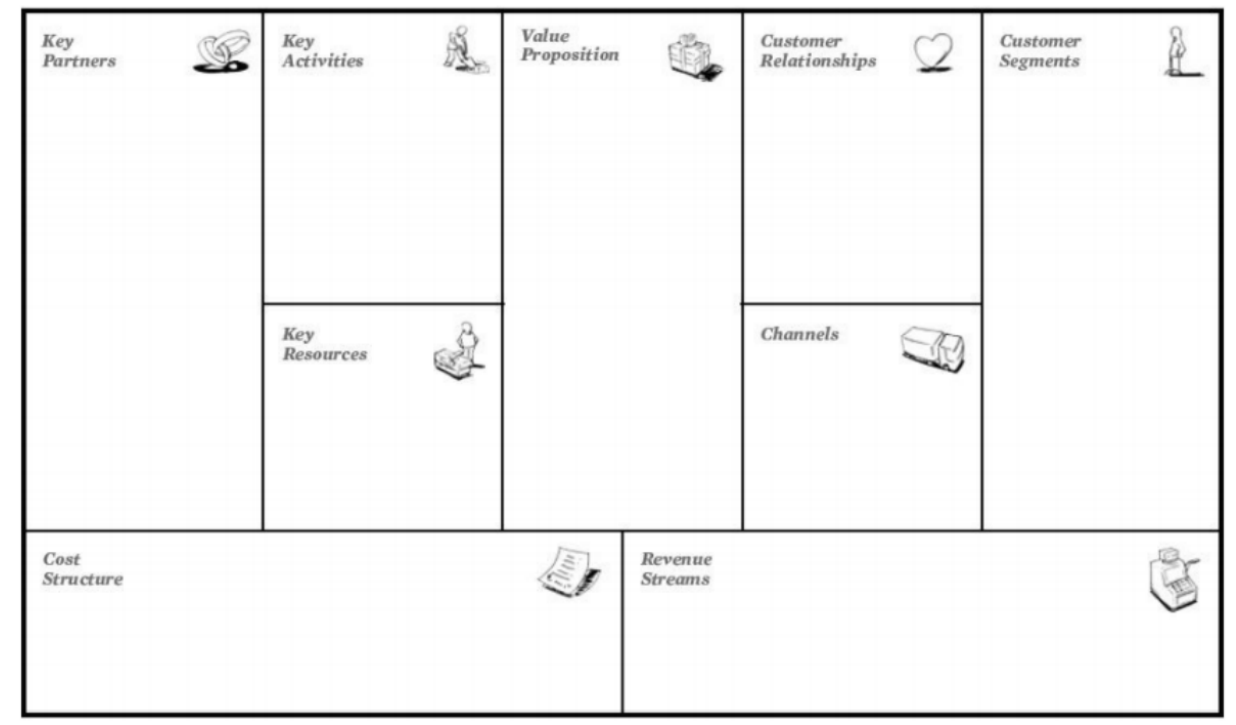

Gambar 1. Komponen bisnis pada model bisnis kanvas (Osterwalder et al., 2010)

\section{HASIL DAN PEMBAHASAN \\ Business Model Canvas (BMC) Pabrik Mie Tjap Tiga Anak \\ a. Customer Segment}

Pasar tersegmentasi adalah pasar yang membedakan segmen pasar berdasarkan kebutuhan dan masalahnya masing-masing atau berdasarkan kebutuhan dan masalah yang serupa tetapi bervariasi (Osterwalder \& Pigneur, 2012). Pabrik Mie Tjap Tiga Anak membedakan segmen pasarnya menjadi pasar konsumen atau B2C (Business to Consumer) yang biasanya adalah ibu rumah tangga, pedagang bakso, pedagang mie ayam, pedagang mie lainnya yang berada di daerah setempat dan di berbagai daerah nusantara. Dari segi geografis pabrik Mie Tjap Tiga Anak terletak di Desa Wlahar Kulon, Kecamatan Patikraja, Kabupaten Banyumas. Pabrik tersebut letaknya yang strategis dan dekat dengan jalan raya. Dari segi psikografis pabrik juga memiliki standar mutu, kualitas dan kuantitas yang baik. Sedangkan dari segi perilaku konsumen sendiri merespon dengan baik karena mie Tjap Tiga Anak ini sudah terkenal sejak lama. Pasar penjual kembali atau B2B (Business to 
Business) yang biasanya adalah dan pasar tradisional seperti Pasar Wage di Purwokerto serta pasar modern seperti supermarket di Purwokerto yaitu Moro dan Rita Pasaraya.

\section{b. Value Propositions}

Produk utama yang ditawarkan oleh Pabrik Mie Tjap Tiga Anak adalah mie kering. Untuk mie kering, value propositions berupa mutu dari mie kering dengan menggunakan bahan baku tepung terigu dengan harga yang murah untuk konsumen dan sudah bersertifikat halal (LPPOM MUI).

a) Harga: Harga produk mie yang di tawarkan oleh Pabrik Mie Tjap Tiga Anak memiliki berbagai tingkatan harga sesuai dengan ukuran dan jenis mie.

b) Akses: Pemasaran produk juga dilakukan secara offline melalui kunjungan langsung yang dilakukan oleh pemilik pabrik ke pasar dan pedagang-pedagang di daerah khususnya kerasidenan Banyumas. Mie dapat dipesan langsung dengan menghubungi pihak owner karena perusahaan menambah segmen pasar tersegmentasi.

c) Kebaruan dan Kemudahan: Produk dikemas dengan menggunakan plastik bening yang tebal dan logo mie Tjap Tiga Anak.

d) Pengurangan Resiko: Pabrik Mie Tjap Tiga Anak bertanggung jawab penuh jika terdapat kerusakan pada produk mie dan bisa ditukarkan langsung ke pabrik.

e) Kinerja: Pabrik Mie Tjap Tiga Anak telah menerapkan SOP Bagi karyawan baik dalam proses produksi hingga pendistribusian.

f) Merek: Merek mie kering di Pabrik Mie Tjap Tiga Anak adalah Mie Tjap Tiga Anak.

c. Channels

Adapun channels atau saluran yang di gunakan oleh Pabrik Mie Tjap Tiga Anak dibawah ini:

\begin{tabular}{|c|c|c|c|c|c|c|c|}
\hline \multicolumn{3}{|c|}{ Jenis Saluran } & \multicolumn{5}{|c|}{ Fase-Fase Saluran } \\
\hline 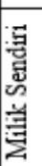 & 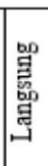 & $\begin{array}{l}\text { - Distribusi } \\
\text { - Penjualan } \\
\text { - Kantor }\end{array}$ & $\begin{array}{l}\text { 1. Kesadaran } \\
\text { - Logo } \\
\text { - Kalender }\end{array}$ & $\begin{array}{c}\text { 2. Evaluasi } \\
-\end{array}$ & $\begin{array}{l}\text { 3. Pembelian } \\
\text { - Datang } \\
\text { langsung ke }\end{array}$ & $\begin{array}{l}\text { 4. Penyampaian } \\
\text { - Word of mouth } \\
\text { - Interaksi langsung }\end{array}$ & $\begin{array}{l}\text { 5. Purnajual } \\
\text { - Bonus }\end{array}$ \\
\hline$\frac{5}{4}$ & 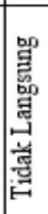 & $\begin{array}{l}\text { - Distribusi } \\
\text { dalam } \\
\text { penjualan } \\
\text { besar }\end{array}$ & & & $\begin{array}{l}\text { Pabrik } \\
\text { - Call center } \\
\text { - Whatsapp }\end{array}$ & & \\
\hline
\end{tabular}

Sumber: Data Primer Diolah, 2021

Gambar 2. Channels di Pabrik Mie Tjap Tiga Anak

\section{d. Customer relationships}

Customer relationships adalah hubungan yang dijalin dengan konsumen yang menggunakan produk dari perusahaan (Alexander Osterwalder \& Yves Pigneur, 2010). Pada pabrik Mie Tjap Tiga Anak menerapkan bantuan personal yang didasarkan pada interaksi manusia yaitu pabrik Mie Tjap Tiga Anak menyediakan call center dan Whatsapp sebagai pelayanan konsumen atau pelanggan agar berkomunikasi untuk mendapatkan bantuan selama proses penjualan maupun setelah pembelian selesai. Sehingga pabrik Mie Tjap Tiga Anak pada customer relationships ini menerapakan hubungan antar manusia yaitu dengan konsumen atau pelanggan menggunakan cara berkomunikasi.

\section{e. Revenue Streams}

Revenue streams merupakan arus pendapatan yang menggambarkan pendapatan yang dihasilkan oleh perusahaan (Osterwalder dan Pigneur, 2012). Revenue streams Pabrik Mie Tjap Tiga Anak didapatkan berdasarkan dari hasil penjualan mie kering dengan jenis mie halus dan jenis mie kasar. Kedua jenis mie tersebut sama-sama memiliki hasil penjualan yang tinggi. Hal tersebut memiliki mekanisme penetapan harga yaitu pabrik Mie Tjap Tiga Anak ini memiliki standar harga yang tetap sesuai dengan jumlah atau ukuran yang telah ditetapkanoleh pabrik serta jenis mie halus maupun jenis mie kasar. Walaupun harga dari bahan baku seperti tepung terigu naik maka pabrik akan tetap menggunakan daftar harga tetap seperti biasanya. Penjualan dari produk Mie Tjap Tiga Anak yaitu ke toko-toko kelontong, pasar, dan supermarket. 


\section{f. Key Resources}

Sumber daya yang dimiliki oleh Pabrik Mie Tjap Tiga Anak yaitu sumber daya manusia. Sumber daya manusia merupakan ilmu dan seni yang mengatur suatu hubungan dan peranan tenaga kerja agar efektif dan efisien membantu terwujudnya tujuan pada perusahaan, karyawan, dan masyarakat (Hasibuan, 2016). Pabrik Mie Tjap Tiga Anak terkait dengan sumber daya manusia memiliki 75 karyawan yang terbagi menjadi beberapa bagian seperti pimpinan pabrik, owner, koordinator, administrasi, dan karyawan produksi.

\section{g. Key Activities}

Aktivitas kunci yang menggambarkan hal-hal terpenting yang dilakukan pada pabrik Mie Tjap Tiga Anak ini yaitu aktivitas produksi. Kegiatan produksi pada proses pembuatan mie kering di Pabrik Mie Tjap Tiga Anak dengan melalui beberapa tahapan untukmendapatkan hasil mie yang baik. Alur dari tahapan-tahapan proses pembuatan mie sebagai berikut:

Aktivitas produksi mie kering di Pabrik Mie Tjap Tiga Anak:

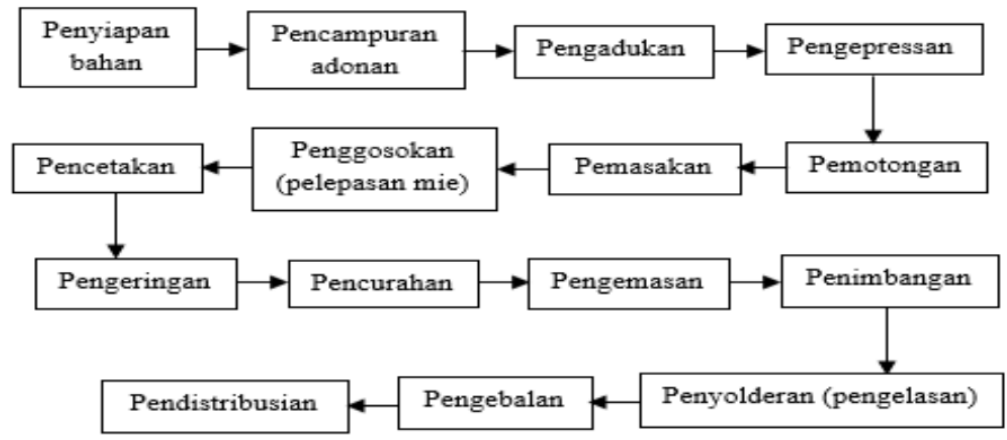

Sumber: Data Primer Diolah, 2021

Gambar 3. Aktivitas Produksi Mie Kering di Pabrik Mie Tjap Tiga Anak

\section{h. Key partnership}

Pabrik Mie Tjap Tiga Anak bekerja dalam memperkenalkan dan memasarkan produknya dengan cara menjalin hubungan dengan baik kepada masyarakat. Adapun pemerintah yang mendukung atas usaha mie kering yaitu pemerintahan Kabupaten Banyumas dengan memberikan izin dalam mendirikan dan menjalankan usaha. Kemudian bahan baku didatangkan langsung dari perusahaan yang ada negara Eropa dan Afrika Selatan. Sedangkan karyawan yang menjalankan proses pembuatan mie kering dan pihak distributor yang mendukung memasarkan produk mie kering tersebut serta pelanggan yang merupakan partner utama yang telah mempercayai produk Mie Tjap Tiga Anak sebagai bagian dari kebutuhan sehari-hari.

\section{i. Cost structure}

Jenis cost structure pabrik Mie Tjap Tiga Anak yaitu yang terpacu-biaya (costdriven) dimana perusahaan meminimalisir pengeluaran agar dapat memberikan harga yang rendah bagi konsumen. Dalam menjalankan bisnisnya, pabrik Mie Tjap Tiga Anak memiliki karakteristik biaya tetap yaitu pengeluaran biaya untuk keperluan biaya pembelian fasilitas dan gaji karyawan. Sedangkan biaya variabel yaitu keperluan biaya pembelian bahan baku dan biaya terkait lingkup ekonomi yaitu biaya pemasaran atau distribusi Mie Tjap Tiga Anak.

Adapun Kerangka Business Model Canvas yang telah dirumuskan dalam bentuk block yang terdiri dari 9 elemen yaitu customer segments, value propositions, channels, customer relationships, revenue streams, key resources, key activities, key partnerships, dan cost structure. 


\begin{tabular}{|c|c|c|c|c|}
\hline \multirow[t]{2}{*}{$\begin{array}{l}\text { KEY } \\
\text { PARTNER } \\
\text { - Pemerintah } \\
\text { - Distributor } \\
\text { - Masyarakat }\end{array}$} & \begin{tabular}{l}
\multicolumn{1}{c}{ KEY } \\
ACTIVITIES \\
- Aktivitas \\
produksi mie \\
kering
\end{tabular} & \multirow{2}{*}{$\begin{array}{l}\text { VALUE } \\
\text { PROPOSITION } \\
\text { - Harga sesuai } \\
\text { dengan ukuran } \\
\text { dan jenis mie } \\
\text { - Pemasaran } \\
\text { secara offline } \\
\text { - Kebaruan dan } \\
\text { kemudahan } \\
\text { - Pengurangan } \\
\text { risiko } \\
\text { - Bersertifikat } \\
\text { halal LPPOM } \\
\text { MUI }\end{array}$} & $\begin{array}{c}\text { CUSTOMER } \\
\text { RELATIONSHIP } \\
\text { - Bantuan personal }\end{array}$ & \multirow[t]{2}{*}{$\begin{array}{l}\text { CUSTOMER } \\
\text { SEGMENT } \\
\text { - Ibu rumah tangga, } \\
\text { pedagang, pasar } \\
\text { tradisional dan } \\
\text { modern }\end{array}$} \\
\hline & \begin{tabular}{l}
\multicolumn{1}{c}{ KEY } \\
RESOURCES \\
- SDM \\
- Fasilitas \\
Pendukung \\
- Finansial
\end{tabular} & & $\begin{aligned} & \text { CHANNELS } \\
& \text { - Logo } \\
& \text { - Kalender } \\
& \text { - Word of mouth } \\
& \text { - After sales }\end{aligned}$ & \\
\hline \multicolumn{3}{|c|}{$\begin{array}{l}\text { - Biaya tetap: Fasilitas dan gaji karyawan } \\
\text { - Biaya variabel: Bahan baku dan distribusi }\end{array}$} & \multicolumn{2}{|c|}{$\begin{array}{l}\text { - Penjualan produk } \\
\text { - Penetapan harga tetap }\end{array}$} \\
\hline
\end{tabular}

Sumber: Data Primer Diolah, 2021

Gambar 4. Kerangka Block Business Model Canvas

\section{KESIMPULAN}

Business Model Canvas (BMC) yang ada di Pabrik Mie Tjap Tiga Anak meliputi customer segment dari Pabrik Mie Tjap Tiga Anak adalah pasar yang tersegmentasi B2B dan B2C. Value proposition adalah bersertifikat. Channels yang digunakan langsung dan tidak langsung. Customer relationship dengan menerapkan bantuan personal. Revenue stream didapat dari hasil penjualan produk mie kering dengan penetapan harga tetap. Key resources terkait sumber daya manusia. Key activities berupa kegiatan produksi mie kering. Key partnership terdiri dari pemerintah, distributor, dan masyarakat. Cost structure merupakan jenis cost-driven dan terdiri dari biaya tetap dan biaya variabel.

\section{DAFTAR PUSTAKA}

Anu H. Bask Markku Tinnilä Mervi Rajahonka, (2010). Matching service strategies, business models and modular business processes. Business Process Management Journal.

Hasibuan, Malayu S.P. 2016. Manajemen Sumber Daya Manusia. Edisi Revisi. Jakarta: Penerbit PT Bumi Aksara.

Mariyani, N. 2011. Studi Pembuatan Mie Kering Berbahan Baku Tepung Singkong dan Mocal (Modified cassava flour). Jurnal Sains Terapan. Vol. 1 No 1:9-11.

Nazir, M. 1999. Metode Penelitian. Ghalia Indonesia. Jakarta.

Osterwalder, A., Pigneur, Y. 2010. Business Model Generation. Canada: John Wiley \& Sons, inc.

Osterwalder, Alexander dan Yves Pigneur. 2012. Business Model Generation. Jakarta: Elex Media Komputindo.

Purnawijayanti. 2009. Mie Sehat (Cara Pembuatan, Resep-resep Olahan, dan Peluang Bisnis). Kanisius, Yogyakarta. $91 \mathrm{hlm}$.

Wallin, J., Chrirumalla, K., \& Thompson, A. (2013). Developing PSS Concepts from Traditional Product Sales Situation: The Use of Business Model Canvas. Springer: Verlag Berlin Heidelberg.

World Instant Noodle Assosiation (WINA). Global Demand For Instant Noodles. http://instantnoodles.org/en/noodles/market.html. 2018. Diakses pada tanggal 5 Juni 2021. 